\title{
A MULHER NA CIÊNCIA: DESAFIOS E PERSPECTIVAS.
}

\section{THE WOMAN IN SCIENCE: CHALLENGES AND PERSPECTIVES.}

\author{
ALVES, Daniela Maçaneiro ${ }^{1}$
}

\section{RESUMO}

Este artigo apresenta atrajetória histórica da mulher no mercado de trabalho e na educação, bem como uma breve discussão sobre a inserção das mulheres no magistério. Destaca a relação da mulher com os cursos eprofissões feminizadas, baseada na divisão sexual do trabalho. Discute a discriminação da mulher na sociedade que veio utilizando a categoria sexo para delimitar o espaçodoméstico e privado como espaço para a mulher. Propõe uma análise das discriminações que as mulheres tem sofrido parapoderem atuar na carreira científica. Diante destas categorias de análise é utilizado o termo gênero para compreender como ocorre o processo de discriminação e manutenção das desigualdadesentre os sexos que até hoje dificultam o acesso da mulher na ciência.

PALAVRA-CHAVE:Mulher.Trabalho.Educação.Ciência.Gênero.

\section{ABSTRACT}

This article presents the historical trajectory of women in the labor market and in education, as well as a brief discussion about the insertion of women in the teaching profession. It highlights the relation of women to the courses and professions feminized, based on the sexual division of labor. It discusses the discrimination of women in society that came using the sex category to delimit domestic and private space as a space for women. It proposes an analysis of the discrimination that women have suffered in order to be able to act in the scientific career. In view of these categories of analysis, the term gender is used to understand how the process of discrimination and maintenance of inequalities between the sexes, which until today, make it difficult for women to access science.

KEYWORD:Woman. Job. Education. Science. Gender.

1. Psicóloga. Pós graduanda em Educação, Diversidade e Redes de Proteção Social - UNESC / Mestranda em Educação - PPGE - UNESC

daniela.alves@unesc.net 


\section{INTRODUÇÃO}

Revista do Programa de Pós-Graduação em Educação - UNESC

O processo histórico da evolução da mulher no mercado de trabalho e na educação foi sendo construído através de um longo e árduo caminho, percorrido em meio ao desenvolvimento de um sistema patriarcal e excludente. Nos últimos anos, é possível perceber as marcantes transformações em relação à participação feminina no mercado de trabalho, principalmente em áreas masculinas, o que tem provocado muitos debates e tem sido objeto de muitas pesquisas.

Durante décadas as mulheres vieram desafiando uma sociedade desigual, patriarcal e machista e foram conquistando espaço nos diferentes campos de trabalho e nas diversas áreas da ciência e da pesquisa.

Elas lutaram paraobter o direito a profissionalização, melhores condições de vida e trabalho, pelo direito ao voto, direito a igualdade salarial, entre outros. Os caminhos percorridos na sociedade industrial e capitalista foram seguidos de exclusão, marginalização, inferiorização e desigualdades, no entanto, não foram fatores que impediram o avanço da mulher na sociedade. A mulher tem na história, um papel importantíssimo, mesmo que muitas vezes colocadas em condições de invisibilidade ou inferioridade.Sua posição de mulher trabalhadora é resultado da revolução industrial, sua condição de trabalhadora assalariada passou a ser analisada dentro dos preceitos morais e legais, pois se duvidava de sua compatibilidade, devido o impacto do trabalho fabril com o seu corpo. (SCOTT, 1991).

Foram muitos enfrentamentos e grandes períodos de invisibilidade, mas hoje a mulher está nos campos mais importantes de muitas profissões, mas não em condição de igualdade. A mulher ainda sofre muitas discriminações e ainda é considerada inapta para muitas áreas, principalmente na ciência, área em queelas tem dificuldades de chegar aos postos mais altos,por serem ambientes considerados propício ao sexo masculino. Diante disto, é preciso reconhecer no percurso histórico o caminho que levou a mulher a chegar a postos de trabalho que antes não eram permitidos a elas, devido à divisão sexual do trabalho, também é importante compreender porque a mulher, mesmo sendo maioria, na educação ainda enfrentam muitas discriminações e não conseguem se manter nas áreas das exatas, Criar Educação, Criciúma, v. 7, no2, julho/novembro 2017.- PPGE - UNESC 
engenharias e em postos mais altos e com maior remuneração no campoda ciência. O presente artigo traz umabrevediscussão a respeito do avanço feminino no campo científico associada àconcepção de gênero que ajudará na compreensão de fatores que contribuíram para a segregação da mulher e que ainda hoje persistem, causando atrasos para sua ascensão e discriminação na sociedade.O artigo trás um breve levantamento histórico das dificuldades encontradas pela mulher na entrada do mercado de trabalho e na educação. Apresenta o processo de feminização da profissão docente pautada na nova divisão sexual do trabalho e em seu objetivo principal discute os enfrentamentos e as conquistas femininas para se tornarem cientistas, refletindo este processo na perspectiva de gênero. Uma reflexão necessária visto que ainda hoje há um conjunto de fatores que discriminam a mulher no mercado de trabalho.

\section{MERCADO DE TRABALHO E EDUCAÇAO}

Historicamente a mulher foi confinada a esfera doméstica, sua vida era conduzida por preceitos morais e religiosos, causas determinantes que a confinavam no ambiente doméstico e a tornaram responsávelpelo cuidado e zeloda vida familiar, do lar, do marido e dos filhos. A sociedade passou a delimitar o que era espaço para a mulher e quais eram seus deveres perante a família, ou seja,o privado (o lar). A partir da industrialização os espaços das mulheres e dos homens foram delimitados entre o público e o privado, isso devidoàstransformações nas áreaspolíticase econômicasque contribuíram para essa divisão de espaços.

Sobre este período histórico Coutinho (1994, p.32) descreve que[...]“as funções domésticas e sociais, começaram a ser separadas, ao mesmo tempo emque começavam a mudar também seus conteúdos específicos, até constituírem o que hoje em dia denominamos âmbito privado(no sentido doméstico) e âmbito público". O que era de intimidade da família, íntimo e afetivo,bem como os cuidados,ficava restrito ao ambiente doméstico, ou seja, o ambiente privado. Já os meios de produção (trabalho) e sobrevivênciacabiamnormalmente aos homens, a eles se destinava o espaço público.Desta forma, o ambiente feminino ficava 
limitadoao trabalho reprodutivo e doméstico. $O$ trabalho feminino não era reconhecido como um trabalho social, por ter um caráter individual e privado,assim:

as mulheres, portanto, donas de casa, passam a ser trabalhadoras que nunca vão conhecer os benefícios que aos poucos a sociedade capitalista nascente vai outorgando a outros trabalhadores[...] Sua dedicação exclusiva ao trabalho doméstico impede e dificulta a participação autônoma das mulheres nos espaços públicos, que ficam restritos aos homens, levando-as a uma marginalidade social. (COUTINHO, 1994, p. 33).

A imposição ao trabalho doméstico contribuiu para que a mulher passasse a cuidar maisdos outros do que de si mesma, provocando uma condição de isolamento social, de modo aviver em condições de subalternidade na sociedade. Estas circunstâncias facilitaram a formação deum conjunto de forças, que criadas pela sociedade patriarcal, foram naturalizando as desigualdades entre osgêneros femininos e masculinos tendo como base as diferenças entre os sexos, que viria a criar a divisão entre os espaços públicos e privados. Uma vez que a mulher se submetesse a essas exigências, ela se ausentava de uma formação profissional, deixava de concorrer com o homem e declarava sua submissão à sociedade. (PINSKY e PEDRO, 2003).Além disso, o casamento, a dedicação total a família, o desempenho no papel de ser mãe, assim como as atividades domésticas exigiam que a mulher estivesse presente no larjunto dos seus em período integral, dificultando assim, o acesso da mulher na sociedade, no trabalho e na educação. Desta forma as obrigações domésticas exigiam da mulher condições que limitavam sua carreira profissional, exemplo disso é que "elas só poderiam trabalhar durante curtos períodos das suas vidas, abandonando o emprego remunerado depois de casar ou terem filhos, voltando ao trabalho mais tarde só no casode os maridos não serem capazes de sustentar a família". (SCOTT, 1991, p 444).

Um dos fatores que contribuem para a segregação das mulheres nas sociedades de classes foi a forma como a sociedade negligenciou a educação para elas. "O acesso desigual à educação foi, e é ainda, em muitos países, um dos fundamentos da desigualdade entre as mulheres e os homens" (KOVALESKI; TORTATTO; CARVALHO, 2013, p.10). Essa desigualdade contribuiu para a subalternidade e a submissão da mulher a postos de trabalhos mais precários e aos mais baixos salários. A educação a elas ofertada foi tardia, pois não cabia àmulhero conhecimento linguístico e matemático e muito menos ser educada para aprender Criar Educação, Criciúma, v. 7, no2, julho/novembro 2017.- PPGE - UNESC 
uma profissão. Era comum o aprendizado de serviços manuais eatividades determinadas pela família, para fins matrimoniais e apoio familiar que seriam ajudar nos serviços domésticos e preparar-se para o casamento e a maternidade.

Além da dificuldade no acesso a escolarização,o fato de receberem a oferta uma educação diferenciada em relação ados homens, pelo simples fato de serem mulheres, afastavaa oportunidade de uma formação básica, e do conhecimento técnico. A partir desta ideia, pautadas nas características que definem ser homem e ser mulher,esta concepção passa a ser afirmadadiante de uma explicação bastante equivocada, para continuar dar ênfase à educação diferenciada,utilizando a ideia de que existem diferenças de caráter biológico que fazem com que haja uma desproporção na educação para ambos os sexos (BARROSO, 1982).

O biológico passou a ser usado como justificativa para diferenciar a educação das mulheres e aumentar as desigualdades entre o sexo feminino e masculino, visto que estes determinantes passaram a serem usados para direcionar segmentos para homens e mulheres, ou seja, a mulher está apta para atuar no magistério e o homem serve para a indústria, num sentido de vocação para avida profissional. Conforme Barroso (1982, p. 52)

As diferenças naturais servem também para emprestar ao conceito de vocação um sentido que leva a consagrar a ordem estabelecida. Os cursos de nível médio e profissional, com currículos que devem atender as especificidades da condição feminina, não só contribuem para reforçar-lhes as desigualdades educacionais, como devem também preparar a mulher para determinadas profissões consideradas mais adequadas ao próprio sexo.

Quando havia necessidade de aprimorar-se nos estudos, primeiro para aquelas de famílias abastadas, a mulher ia aprender apenas o necessário e conveniente para sua posição social. A educação da mulher, principalmente no Brasil, era limitada a educação mais moral, direcionada aos interesses das famílias e sociedade. No Brasil, desde o Império, a mulher deveria ser ensinada apenas por professoras do sexo feminino que educassem dentro dos preceitos morais e as preparassem para habilidades manuais. "Na realidade, o fim ultimo da educação era para atuar no espaço doméstico e incumbir-se do cuidado com o marido e os filhos, não se cogitando que pudesse desempenhar uma profissão assalariada." 
(ALMEIDA, 1998, p.19). Devido a isso o número de meninas a serem educadas era quase mínimo e poucas eram ensinadas a ler e escrever.

Na Europa, no século XX quando o cenário começou a mudarno decorrer do processo de industrialização, houve a necessidade da mulher entrar no mercado de trabalho para suprir a falta de mão de obra masculina. (LAGRAVE, 1991).Mas, para isso ela precisava de certos conhecimentos, principalmente para ocupação nas carreiras intelectuais e liberais fazendo com que a educação se tornasse indispensável, de modo que foram criadas vagas para elas em cursos profissionalizantes. Mesmo com a necessidade da educação formal além da doméstica, que crescia conforme as necessidades da sociedade,a educação formal feminina era menos importante do que a masculina, fazendo com que o ensino público se tornasse um divisor para a educação delas.

Com a abertura do ensino público para as mulheres, novas possibilidades foram sendo criadas, mas para chegar a uma educação que relacionasse ao preparo profissional da mulher, a luta foi longa e árdua. (PINSKY; PEDRO, 2003). É uma luta antiga e logo após a Segunda Guerra Mundial as exigências foram ficando maiores, sendo que a educaçãotécnica passa a ser uma exigência para suprir as necessidades das indústrias. "O ensino técnico e profissional e o ensino geral elevam o nível de qualificação dos operários, mas tem pouco efeito sobre o das operárias" (LAGRAVE,1991, p.510). Como o mercado pós-guerra necessitava de mão de obra e o mínimo de conhecimento técnico , as mulheres iam ficando de fora, já que não possuíam qualificação, entrando, desta forma na lógica de racionalização do trabalho e nessa lógicase distinguia o trabalho qualificado do não qualificado, contribuindo assim para menor garantia de direitos, menores salários ereforçando as qualidades femininas naturais parao preenchimento dos cargos que não exigiam qualificação. (LAGRAVE, 1991).

Um dos motivos alegados para que este atraso fosse consolidado foi, segundo Carvalho (2013, p.10) "[...] a incapacidade intelectual das mulheres para entender as ciências mais abstratas, como a matemática, a física, a filosofia”. O discurso de inferioridade da mulher era prontamente atribuído ao seu sexo inferiozando-a por sua condição biológica. Esse discurso influenciou diretamentena educação através da filosofia positivista, que de acordo com Almeida (1998, p.41) "o Criar Educação, Criciúma, v. 7, no22, julho/novembro 2017.- PPGE - UNESC 
pressuposto da inferioridade biológica e intelectual feminina levou o positivismo, no século XIX, a considerar natural o alicerçamento dos homens no poder, baseados na diferença natural entre os sexos."Essa ideia tinha como justificativa as características ditas femininas que incluíam afetividade, o amor,a condição moralreafirmando assim a importância da presença da mulher no lar.

Mas, com o avanço industrial, a supremacia do capitalismo, os avanços tecnológicos e mercadológicos, novas configurações na sociedade foram necessárias. Neste contexto a mulher passou a se inserir no mercado de trabalho e a exigir que direitos fossem consolidados e que houvesse igualdade de direitos frente a várias condições de trabalho. Com a expansão da educação, que afetou consideravelmente a vida das mulheres (não de forma negativa), pois muitas passaram a ter acesso ao domínio público da cultura e ampliar seus horizontes e algumas, puderam inclusive, tornar-se elas próprias produtoras de conhecimento, ao investirem,principalmente na escrita. Assim, suasexigências começaram a ser reivindicadas conforme iam ocupando os espaços educacionais. A luta pela ocupação do espaço educacional e de formação profissional foi bastante difícil e longa, principalmente porque a oferta de uma educação diferenciada para ambos os sexos, como já visto não fornecia condições para ingressar no ensino superior. O ensino considerado secundário também não alavancou, pois a educação era limitada, mais moral e de cunho social, do que formação intelectual e profissional. 0 ensino universitário não era cogitado para o sexo feminino e elas só tiveram acesso a partir do século XIX, atravésdas instituições destinadas ao magistério. É importante ressaltarque o ensino superior não fugia a lógica capitalista da divisão sexual, que de acordo com Lagrave(1991, p.523),

\begin{abstract}
a Escola classifica e desqualifica de um modo que modela as raparigas em função de destinos profissionais prováveis, isto é, femininos. [...] A escola quer-se emancipadora quando ela é conservadora, no sentido em que inventa novas áreas que, ao abrigo de uma diversificação de saberes, instauram opções destinadas a manter 0 afastamento das diferenças entre rapazes e raparigas.
\end{abstract}

A instituiçãoescolar, que limita e delimitam os espaços, as diferenças é de acordo com Louro (2003, p. 89)“[...] atravessada pelos gêneros; é impossível pensar sobre a instituição sem que se lance mão das reflexões sobre as construções sociais e culturais do masculino e feminino."E são estas instituições normalizadoras e Criar Educação, Criciúma, v. 7, no2, julho/novembro 2017.- PPGE - UNESC 
disciplinares que vão se transformando historicamente, conforme exigência do patriarcado. Estas diferenças e distinções colaboram para a presença maciça das mulheres em áreas que foram sendo feminizadas como, por exemplo Letras, Pedagogia e Psicologia, fazendo da Educação Escolar para as mulheres uma grande colaboradora ao aumento das desigualdades entre os sexos, "o efeito mais sutil e violento da dominação masculina no sistema escolar é realmente o de fazer assumir pelas mais desmunidas as escolhas que presidem a sua própria desvalorização". (LAGRAVE, 1991, p.524). E colocando-as em posições determinadas para sua condição (condição criada por um sistema) sem chance de escolhas, as mulheres contribuem para manter as características afetivas e morais exigidas pela sociedade.

Assim, conforme Ferrand (1994, p.361),

"consideradas biologicamente ineptas, por razões de natureza, à prática das humanidades clássicas (latim e grego) até 0 inicio do século $X X$, as mulheres hoje tem obrigação de serem fortes em literatura. Suas inaptidõesparecem então se concentrar essencialmente nas ciências e mais particularmente na matemática".

Com os estudos avançados das funções cerebrais ficava clara a inaptidão das mulheres para algumas disciplinas, elas passariam então a ser consideradas menos dotadas para as ciências. (FERRAND, 1994). A condição biológica foi utilizada para justificar as inaptidões conforme o sexo e forame ainda são determinantes para colocaremas mulheres em formações consideradas apropriadas a sua condição física e psíquica. De acordo comFerrand (1994, p.362) "para alguns, com efeito, em razão de uma socialização específica, as meninas não poderiam adquirir as qualidadesnecessárias: sentido do espaço, agressividade, abstração, gosto pelo jogo,competitividade, qualidades aparentemente requeridas para fazer ciência".Esta argumentação se baseia em grande parte pelas diferenças comportamentais entre homens e mulheres e carrega junto "o velho argumento segundo o qual as mulheres não são feitas para as ciências, devido à sua natureza [...] Longe de acabar com os preconceitos a respeito das mulheres vai, ao contrário, fornecer novas justificativas".(KOVALESKI; TORTATO; CARVALHO, 2013, p.10). É um argumento antigo, mas que ressurge a cada século, segundo o autor, e vem discriminando e excluído as mulheres de campos específicos da ciência. 
Diante destes argumentos, apresentados e defendidos na sociedade patriarcal, além da educação específica e adequada para as meninas e dos cursos adaptados para a formação da mulher, algumas profissões também foram enraizando a ideia de considerar o sexofemininoe suas inabilidades específicas para desempenhar certas funções. Entre as mudanças que marcam, de forma mais evidente, esse processo de transformação está a feminização da profissão do magistério, que fomentou a profissionalização da mulher na Educação e no mercado de trabalho. E com a sociedade mergulhada nesta visão mercadológica discriminatória, baseada em diferenças sexuais estabelecidas biologicamente,foi se desenvolvendo uma condição de trabalho que beneficiavam o sexo masculino, assim para o trabalhoqualificado (ocupado pela maioria dos homens) há uma condição melhor de remuneraçãoepara o trabalho feminino considerado não qualificado, a mulher alcança menores salários, sendo seu trabalho desvalorizado e discriminado. Mas, este processo discriminatório não foi inicialmente sentido pelas mulheres como uma forma de descriminação, pois houve um processo de naturalização e as mulheres incorporaram as responsabilidades no lar e como mãe. Assim, logo que consegue alcançar os caminhos da educação,esta condição passa a ser uma forma de libertação, contribuindo para que elas se inserissem e se socializassem na sociedade.

\section{A FEMINIZAÇAO DA PROFISSÃO DOCENTE PAUTADA NA NOVA DIVISÃO SEXUAL DO TRABALHO}

O homem e a mulher são feitos para o mesmo trabalho, percebem a mesma realidade e têm as mesmas necessidades, assim neste contexto a sociedade capitalista não deveria impor a mesma condição e argumentaçãobaseadasnas diferenças sexuais. Esta é a reflexão que a autora Yannoulas(2011) faz ao discutir sobre a diferença sexual que conduziu à discriminação da mulher em virtude do seu sexo.Discriminação pautada nas diferenças, nos discursos, e enraizados na cultura, parte de uma história repleta de argumentações que mostram a mulher como um ser mais fraco e inabilitado a certas condições. 
É neste sentido que a Almeida (1998, p.63) nos conta o quanto a história tem nos mostrado queo trabalho feminino "tem sofrido pressõese tentativas de controle ideológico e econômico por parte do elemento masculino e das instâncias sociais [...]". O que nos situa sobre o longo período em que se instaurou um processo regulador e estabeleceu métodos de normatizaçãoexigido pelo patriarcado e que foi sendo evidenciado como uma forma de controle social exercido sobre as mulheres . A perversidade instituída às colocou como seres humanosmenos capazes, inferiores e que não se importavam com uma condição de trabalho desigual e salários inferiores.

Mesmo que homens e mulheres tenham direitos iguais, conforme o princípio da igualdade que vem se consolidando até hoje, ainda existe um conflito referente à existência de uma identidade feminina e uma masculina diferenciada. $O$ fato é que estas identidades se relacionam através de normas e condutas, além de espaços específicos para cada sexo. São estas identidades que permitiram em um contexto de igualdade formal discriminar na prática os seres humanos em virtude de seu sexo biológico. (YANNOULAS, 2011).

As argumentações em bases biológicas, vistas anteriormente, contribuíram para legitimar a discriminação das mulheres não só na educação, mas também no mercado de trabalho. Estes argumentos acabaram contribuindo para o processo de feminização das profissões, devido à ideia de que homens e mulheres por sua condição biológica e natural realizam tarefas diferentes. Essa nova divisão sexual do trabalho, produzida pela industrialização deu novos significados aos conceitos de trabalho, o público e o privado e o feminino e masculino(YANNOULAS, 2011).

Com a divisão sexual do trabalho e a feminização da profissão docente, foram criadas oportunidades para a entrada do sexo feminino no magistério, pois se entendia que a mulher realizaria esta função com melhor desempenho, visto queera associada à domesticidade e maternidade.Tal concepção usa toda a sua forma de poder para "reforçar os estereótipos e a segregação sexual a que as mulheres estiveram submetidas socialmente ao longo de décadas, por entender-se que cuidar de crianças e educar era missão feminina e o magistério revelar-se eu lugar por excelência."(ALMEIDA, 1998, p.64). Nestas condições as mulheres, consideradas excelentes educadoras, encontravam aptas para a profissão do magistério e Criar Educação, Criciúma, v. 7, nำ2, julho/novembro 2017.- PPGE - UNESC 
exerceriam duas funções muito bem reconhecidas e valorizadas socialmente: a de professora e mãe. Por isso,esta profissão tornou-se tão importante para a sociedade, pois estaria educando e cuidando de um grupo a ser formado com propósitos capitalistas e dentro dos preceitos morais de que a sociedade precisava.

Coutinho (1994, p. 40) pontua que,

estes discursos contribuem para conformar a subjetividade feminina, fazendo parte da cultura entendida como lugar de identificação e de criação de sentido e, como consequência, são reproduzidos, por sua vez, pela própria mulher em seu papel de socializadora e mediadora, em sua função de reprodutora de valores e normas que sustentam esta forma de organização social baseada na divisão de trabalho por sexo.

Desta forma, a mulher passa a ser um produto cultural de subordinação, cuja essência do seu papel enquanto educadora era influenciado por um idealmoralista para que se formasse uma profissional reconhecida pela sociedade e instituições de poder. Na prática, as mulheres que se tornaram profissionais docentes e estariamocupando um posto de trabalho que acarretaria para a sociedade um meio de produção rentável devido o papel que desempenharia.

Embora profissionalmente reconhecidas,

elas se localizaram na esfera social, mas não falam por si próprias, não produzem conhecimento, perdem sua individualidade, visto que estendem as tarefas de cuidado privado para uma esfera que não é publica no sentido original grego, porém social (YANNOULAS, 2011, p.278).

Assim, diante do que já vimos até aqui,pautada nas diferenças físicas, psíquicas e biológicas reforçadas pelasociedade patriarcal e suas condições impostasque levaram a mulher a tomar os caminhos traçados por um padrão social machista, nos permite discutir um processo bastante significativo para a mulher que viesse a seguir uma carreira profissional, que seria optar por um trabalho já feminizado. Neste caso uma das mais comuns profissões, apropriada (segundo a sociedade) ao sexo feminino, conforme as concepções sociais da época era a Docência. Não nos cabe aqui falar especificamente da docência enquanto profissão, e tampouco dizer que foi uma profissão que segregou as mulheres ou the causou algum mau, pelo contrário vamos falar sobre como ela foi transformada num trabalho predominantemente feminino, e posteriormente de como ela impulsionou a carreira da mulher emoutras esferas educacionais e de formação. 
Com o direito a educação conquistado, as mulheres passaram a ocupar cargos antes ocupados só por homens. No caso do ensino escolar, por preceitos morais, a educação de meninas passou a ser feita por mulheres, o que expandiu a profissão do magistério para a ocupação feminina como educadoras. Desta forma houve um aumento na demanda da profissão de professora, de modo que asfunções de educar e cuidar das crianças passou a serfeitas praticamente por mulheres, o que conduziu a ideia de que a Escola fosse um lugar de trabalho para elas. E com isso a profissão do magistério passou a ser feminizada. Analisando estas mudanças é possível perceber discursos que sustentam esse processo, que de acordo com Yannoulas(2011, p. 285), baseavam-se nasseguintes premissas:

\begin{abstract}
a) discurso político que fomentava a incorporação das mulheres aos incipientes sistemas educacionais como guardiãs da cidadania, b) um discurso da administração cientifica do trabalho que identificava nas mulheres mão de obra barra e disponível, e finalmente, c) um discurso pedagógico que cientificamente destacava as habilidades femininas para lidar com as crianças nas novas perspectivas educacionais que fundamentavam o ensino na persuasão e não na imposição.
\end{abstract}

Estes discursos davam a mulher uma condição profissional que era atrelada a esfera reprodutiva. Com isso a produção do saber deixou de ser reconhecida socialmente e passou a ser uma condição estabelecida adequada a identidade feminina, pautada nas suas habilidades do cuidar, educar e vigiar.

No Brasil, por exemplo,na década de 1930 esta condição“atribuía as mulheres o papel de regeneradoras morais da sociedade, o que se faria principalmente pela sua inserção no campo educacional.” (ALMEIDA, 1998, p. 66). A partir desta premissa cabia a professora, moldar e condicionar os indivíduos às práticas morais e sociais impostas para o bom convívio, formando assim um sujeito consciente dos seus deveres com a sociedade, de modo que não desvirtuasse das reais intenções propostas pela educação.

Diante destas premissas, a representatividade da mulher no magistério através da condição de professora, mesmo diante de certo controle social, "[...] foi praticamente a única em que as mulheres puderam ter o direito de exercer um trabalho digno e conseguir maior inserção no espaço público, dado que os demais campos profissionais lhes foram vedados". (ALMEIDA, 1998, p. 23).Nestas circunstâncias, a feminização da profissão docente contribuía para gerar certa Criar Educação, Criciúma, v. 7, no2, julho/novembro 2017.- PPGE - UNESC 
visibilidade ao sexo feminino, seja na esfera politica ou na esfera social, o que certamente gerou um grande movimento na ocupação destes cargos. Como elas foram consideradas aptas a preencher todas as condições exigidas para a escola elas passaram a se profissionalizar e ocupar estes espaços, reivindicando para si a inserção nos espaços públicos.

Entretanto ao optar pela docência e passar a ocupar este espaço, em condição de discriminação sexual, foram criadasoportunidades para a mulher ocupar majoritariamente o corpo docente,ficando evidente que "quanto mais elevado o nível de ensino, menor a participação das mulheres no corpo docente. [...] da mesma forma, a participação de mulheres docentes universitárias faz-se desigualmente de acordo com o prestigio da instituição [...]."(BARROSO, 1982, p. 78-79). Na hierarquia, no âmbito educacional, quanto maior o posto, menor é a participação da mulher, tornando-se quase invisíveis, principalmente em cargos ocupados na direção e supervisão. Nos cargos melhor remunerados, valorizados e que exigiam outras habilidades as mulheres não estão presentes. Além disso, com a efetiva entrada das mulheres na ocupação destes cargos docentes, houve uma gradativa diminuição do seu salário. (BARROSO, 1982).

Desta forma, "a concentração das mulheres nos empregos feminizados, portanto pior remunerados, o seu mais difícil acesso a níveis hierárquicos superiores, a sua menor qualificação bastam apara explicar a manutenção do afastamento entre os salários masculinos e femininos" (LAGRAVE, 1991, p.527529). Conforme as normas mercantilistas e capitalistas um emprego feminizado automaticamente gera uma baixa remuneração e a contraponto contribui para uma condição salarial mais alta para o sexo masculino. Além disso, os empregos são mistos, a lógica social discriminatória intervém para invalidar qualquer tentativa de igualdade entre homens e mulheres.

Mesmo diante de todos estes fatores na feminização da profissão docente pode se dizer que não foi apenas uma condição subalterna e de submissão da mulher. O magistério para muitas foi também uma condição de libertação, de acesso ao mercado de trabalho e de uma condição de vida mais autônoma. "O trabalho que desenvolveram no magistério fez parte de um movimento muito maior na educação e na sociedade, por desafiar os preconceitos do patriarcado e da existência feminina Criar Educação, Criciúma, v. 7, no22, julho/novembro 2017.- PPGE - UNESC 
num meio eminentemente masculino". (ALMEIDA, 1998,p. 78). O magistério impulsionou a carreira feminina nos diversos níveis da educação e contribuiu para a formação de pesquisadoras que posteriormente foram se inserindo nas áreas da ciência e da tecnologia.

\section{A MULHER NA CIÊNCIA: OS ENFRENTAMENTOS E AS CONQUISTAS FEMININAS NA PERSPECTIVA DE GÊNERO.}

Após uma análise histórica de como se configurou a luta da mulher para ter acesso ao trabalho e a educação podemos compreender melhor porque ainda existem dificuldades na participação feminina em algumas carreiras, principalmente na área da Ciência. Sua participação neste campo é recente e teve início há pouco tempo, em meados do século passado. Este acesso só ocorreudevido ao grande esforço das mulheres na busca pela igualdade de direitos e conformea necessidade de desenvolver atividades estratégicas (MARQUES, 2009). A progressiva participação feminina no mundo do trabalho e nas carreiras até então consideradas masculinas e as batalhas que elas travaram para conquistar a profissão desejada buscando romper com as discriminações impostas socialmente, foi de longe um processo fácil.

Nas últimas décadas, principalmente no Brasil, as mulheres tem vivenciado profundas transformações que tem influenciado diretamente em suas vidas e carreiras. Houve um salto nas matrículas em cursos superiores contribuindo para a formação acadêmica de um grande número de mulheres, além da inserção contínua no mercado de trabalho, $\mathrm{o}$ fato de se tornarem mais independentes $\mathrm{e}$ emponderadas, de casarem mais tarde e optarem por um número menor de filhos contribuem para a ascensão delas na sociedade.(MELO; RODRIGUES, 2006). No entanto, os avanços pontuados ainda trazem consigo barreiras sociais que afetam a participação da mulher em algumas carreiras, principalmente devido a todo o processo de divisão sexual que vimos anteriormente. A cultura em que vivemos contribui para criar desigualdades entre os gêneros e permitem crer que a 
capacidade feminina ainda é limitada.Além disso, conforme Gomes e Siqueira (2010, p 1-3)

\begin{abstract}
a entrada das mulheres na universidade deu-se de forma gradual; mesmo tendo acesso ao mundo acadêmico, o fizeram principalmente nas áreas de humanas sendo "culturalmente" excluídas da área tecnológica e da saúde. Mesmo hoje percebe-se que há preponderância feminina nas áreas humanas, caracterizando-se quase nichos femininos. [...] Tal cenário nos leva a pensar nas dificuldades das mulheres na academia, nos embates que travam, nos entraves à progressão na carreira, entre outros aspectos. (GOMES; SIQUEIRA. 2010, p. 1-3).
\end{abstract}

Tanto na posição de acadêmicas, quanto de docentes os nichos femininos são posteriormente as carreiras mais feminizadas, no caso da profissão docente também é possível perceber que existe essa divisão.Ela se dá conforme o campo de formação, como por exemplo, licenciaturas possuem muitas docentes, nas engenharias mais docentes masculinos, assim como nos cargos mais altos de gestão, cientista/pesquisador, resumindo "há uma divisão sexual dos espaços, pautada numa hierarquia, tanto na universidade (campo de formações), quanto no mercado de trabalho - âmbitos estes diretamente vinculados", assim completa Gomes e Siqueira (2010, p. 2)

Contudo,o aumento da escolaridade ea inserção feminina nos diversos cursos superiores trouxenovas oportunidades que possibilitaram o avanço da participação da mulher, embora muito timidamente, no campo científico da pesquisa, cujapredominância é totalmente masculina.Devo dizer que o fato de aqui conter a palavra "timidamente" não é com o intuito de dizer que a mulher só agora vem ocupando este espaço, mas sim porque é um campo elitizado, onde um grupo intelectualmente denominado cientista compostos por sua maioria homens ocupam o espaço numa relação de poder, o que acarreta na tímida presença da mulher.A participação feminina neste território não é insignificante, mas sim tardia eseus méritos foram poucos conhecidos, visto que órgão como a Organização das Nações Unidas para a Educação, Ciência e Cultura (UNESCO) e o Conselho Nacional de Desenvolvimento Científico e Tecnológico (CNPq) lançaram campanhas para escrever sobre elas e premiá-las pelo seus trabalhos. O reconhecimento da participação feminina na ciência, principalmente no Brasil, é fundamental para o progresso do conhecimento, devido a esta importância foi divulgado na página doCNPq, um espaço destinado "a mulher na ciência" ondeé possível ler sobre as Criar Educação, Criciúma, v. 7, n², julho/novembro 2017.- PPGE - UNESC 
"Pioneiras da Ciência no Brasil"documento que foi lançado pela primeira vez em 2006. Neste documento é possível conhecer acontribuiçãodas cientistas para o acesso do saber e poder "do saber, porque cada uma delas teve um importante papel para sua área de conhecimento. Do poder, porque provaram que as mulheres não são só aptas para a ciência quanto esta não pode prescindir de sua contribuição" (CNPq).

Com o avanço das carreiras científicas e tecnológicas as mulheres puderam participar mais, mas de forma desigual. Sua participação teve maior concentração em áreas como a das ciências biológicas e a sociais, ficando em desvantagens nas áreas como as da física, tecnologias, engenharias e computação (MARQUES, 2009).

No Brasil, todo este avanço é recente, assim esta situação "surge como possível elemento transformador de um quadro solidamente estruturado há séculos: o fato da pesquisa cientifica ser empreendido por e para indivíduos do sexo masculino" (GUEDES, 2012, p. 1). Por ser uma área maismasculina, os campos científicos foram caracterizados por relações sociais e marcas culturais sexistas que contribuem para a escassez da presença das mulheres nas áreas das ciências exatas (BANDEIRAS, 2008). Um campo conduzido por relações de poder, e assim como tantos outros campos de trabalhos não eram lugares consideradosadequados para mulheres, a não ser que ocupassem o cargo de assistentes, secretárias entre outros. Desta forma a participação feminina na pesquisa era quase invisível e sua atuação foi na informalidade como descreveu Gomes e Siqueira (2010, p. 3): "ao longo de muitos séculos sendo negado o acesso feminino ao "lócus formal" da Ciência, as mulheres somente ganharam acesso ao conhecimento científico por canais informais".De acordocom Bandeiras (2008, p. 212), "a exclusão da presença feminina não era apenas explicitada em termos da naturalização, pois era fartamente justificadapela incapacidade e pelo obscurantismo das mulheres,ao contrário do dos homens, que se notificavam pelas luzes e pela objetividade". Condição instaurada numa sociedade capitalista, onde os homens considerados superiores ocupavam espaços que lhe davam condições de serem reconhecidos comodominantes. 
O que chama atenção ao discutir este tema é que a escolha das carreiras, como a da ciência, iniciam na educação escolar. Porém, é na escola que há um direcionamento a certa tendência "natural" nas escolhas das profissões consideradas adequadas aos meninos, e as consideradas adequadas às meninas. ParaFerrand (1994, p.363), este é um efeito do processo histórico de dominação, em que o masculino sobrepõe-se ao feminino e delimita os campos do saber e do conhecimento e os torna "restritospara as mulheres que mais que para os homens, excluindo aqueles campos do poder, ao mesmo tempo em que faz crer na abertura total dos possíveis aos dois sexos coisas que o estabelecimento da escola mista permite supor".Mesma escola, mesmo espaços, no entanto o direcionamento delas nas escolhas das aulas e dos cursosfoi por muito tempo definidos por uma questão sexual, onde elas estão culturalmente envolvidas por uma concepçãopatriarcal e dominante que ainda carrega a ideia de inteligência inferior onde cria-se umafalsa ilusão de que a menina ou mulher não é capaz de desenvolver e praticar certos conhecimentos e as fazem entender isso como natural, e que na verdade é algo construído socialmente. Assim estes fatores contribuem para maior discriminaçãoda presença da mulher nas áreas mais masculinizadas.

Não há como fazer uma análise sobre a ocupação e permanência das mulheres no campo científico sem passar por toda a discussão das diferenças sexuais e biológicas estabelecidas socialmente, pois contribuíram para uma divisão sexual do trabalho e a subalternidade da mulher em muitas profissões.E embora elas venham se destacando em vários campos (politico, científico, tecnológico) as desigualdades que as diferenciam do sexo masculino ainda as rodeiam. "Apesar da ascensão irreversível da atividade feminina, apesar da manutenção das mulheres no mercado de trabalho, mesmo casadas e mães de família, permanece forte na representação uma visão diferenciadas das careiras profissional segundo 0 sexo"(FERRAND, 1994, p. 363).

Mesmo com a diminuição das desigualdades na ocupação das carreiras educacionais, cientificas e tecnológicas ainda persiste a forma como as organizações relacionadas a estas áreas percebem 0 trabalho da mulher, considerando como "o desempenho profissional ou ao compromisso com a carreira, tidos como inferiores aos dos homens devido à dedicação à família, e seus efeitos Criar Educação, Criciúma, v. 7, n², julho/novembro 2017.- PPGE - UNESC 
colaterais, como o escasso acesso a altos cargos acadêmicos e a remuneração relativamente menor". (MARQUES, 2009).Por isso torna-se essencial que neste debate esteja presente a discussão de gênero, pois o gênero,

é o modo como as culturas interpretam e organizam a diferença sexual entre os homens e mulheres. Sua principal característica esta na mutabilidade, isto e, na possibilidade de mudança na relação entre homens e mulheres através do tempo(YANNOULAS, 1996 apud YANNOULAS, 2011, p. 284).

Assim sendo, o gênero adquirido pela cultura "é a forma social que adquire cada sexo, o que se obtém através do processo de socialização [...]". (COUTINHO, 1194, p. 41). Para Scott (1995) o gênero possui uma "conexão integral entre duas proposições: 1) o gênero e um elemento constitutivo de relações sociais baseadas nas diferenças percebidas entre os sexos e 2) o gênero e uma forma primária de dar significado às relações de poder". Desta forma, a autora entende que é nesse campo, do gênero, que as relações de poder se constroem e são legitimadas.

Mas o gênero, termo adotado como comum aos dois sexos, considerado uma construção social que entende e compreende as diferenças não o torna um termo que justifique ou defenda as desigualdades, pelo contrário, ele vem para tornar a discussão sobre homens e mulheres mais democráticas, de modo que se reconheçam as diferenças e se discuta formas de eliminar as discriminações e violências. (ALMEIDA, 1998,YANNOULAS, 2011). É importante ressaltar e aí me apoio nas ideias de Saffiot (1994), a defender que neste contexto histórico pontuado até aqui,,que esta categoria não vem negar as diferenças, mas nos leva a entendêlas como resultado de uma relação mediada pela cultura. Ainda reforça que a diferença e igualdade não são isoladas, mas sim uma condição da outra.

Portanto, o conceito de gênero não se refere especificamente a um ou outro sexo, mas sobre as relações que são socialmente construídas entre elas. Estas relações estão imbricadas, por sua vez, com as relações de poder que revelam os conflitos e as contradições que marcam a sociedade. (ALMEIDA, 1998, p.40)

É através do gênero e das relações de poder existente entre homens e mulheres, que poderemos compreender melhor como a ciência tornou-se um espaço masculinizado e restringiu acesso às mulheres, visto que se percebe na ciência práticas impregnadas desexísmo e androcêntrismo. São heranças sociais e culturais que condicionam as diferenças e os interesses. Além disso, os Criar Educação, Criciúma, v. 7, n², julho/novembro 2017.- PPGE - UNESC 
"estereótipos como o da aptidão masculina para as ciências influenciam as mulheres no momento da escolha profissional e as afastam de determinadas áreas". (MARQUES, 2009, p.31)

Sabe-se da presença da mulher nestes campos e são figuras conhecidas em muitas áreas como na história da Botânica, na Farmácia, na Medicina, desta forma é importante compreendermos o porquê que os saberes da ciência, descobertos por elas, poucos foram reconhecidos e divulgados.Para as mulheres foram escassas as oportunidades e "a repressão às mulheres no campo intelectual agravou-se com o crescimento das universidades e o monopólio que elas se arrogaram sobre os saberes, sua transmissão e a prática das profissões intelectuais", segundo Kovaleski, Tortato e Carvalho(2013, p.16). De acordo com os autores, as mulheres são totalmente capazes para o campo científico, no entanto a repressão cultural e social sofrida por elas tem contribuído para a disparidade de gênero desde que elas se aventuraram nos campos científicos.

Atualmente, apesar de as mulheres ocuparem massivamente os cursos superiores e novas cadeiras na docência universitária outras desigualdades foram sendo instauradas, como as diferenças salariais, inclusive para as que ocupam os mesmos cargos que os homens, o reduzido número de mulheres nos cargos de chefia, principalmente nos campos de pesquisa e a discriminação em si, pelo simples fato de ser mulher,que dificulta o acesso delas nos cursos como o das engenharias. Conforme descrevem os autores pré-citados "uma estrutura social que prega a maternidadecompulsória aliada a uma carreira científicaque exige dedicação em tempo integral é uma forte causa de exclusão" (KOVALESKI, TORTATO, CARVALHO, 2013, p. 24).

É assim que o capitalismo e a forma como ele se instala e as relações de gênero que nele se configura, que de forma avassaladora vai construindo barreiras para que a mulher continuesubalterna e permaneça em carreiras feminizadas. A mulher tempredisposição ecapacidade de ir moldando-se e ocupando lugares masculinos, mas dificilmente os homens ocupam lugares femininos, se assim fosse seriaum grande retrocesso do capitalismo, homens perdendo seus postos. Pensando assim, para que se mantenha este sistema, ainda persiste o processo discriminatório nas diversas carreiras profissionais, exigindo da mulher 0 Criar Educação, Criciúma, v. 7, no22, julho/novembro 2017.- PPGE - UNESC 
compromisso de dar contado trabalho remunerado, mas também do trabalho reprodutivo, fazendo com que muitas desistam no meio do caminho.

Tudo isso dificulta ainda mais a participação da mulher nas carreirasligada ao campo da ciência, cujo tempo deve ser ocupadocom dedicação total, e o tempo, a qualidade dele para homens e mulheres é diferenteporque como vimos antes, 0 trabalho doméstico é destinado a elas, e mesmo com muitos investimentos, a ajuda do homem nesta tarefa é mínima. Sobrecarregada a mulher não consegue aproveitar a oportunidade de uma carreira sólida.

Com a sobrecarga em cima da mulher, o homem tem para si tempo de sobra e pode se dedicar integralmente à pesquisa e carreira científica.Esseexcesso de carga é motivo para que muitas mulheres se afastem das carreirase até abram mão de uma posição mais rentável."É claro que nestas condições de controle e barreiras para que pudessem produzir conhecimento científicos, com inúmeros obstáculos que the eram impostos (o que nunca aconteceu ao universo masculino), a produção científica feminina teve um desenvolvimento tardio e algumas cientistas ficaram na invisibilidade até hoje”. (CARVALHO,CASAGRANDE, 2011, p.26).

As barreiras foram muitas e seu sucesso pouco reconhecido, visto que os homens e suas realizações são ainda hoje mais valorizadas do que os das mulheres, principalmente no meio acadêmico. Apesar desta discrepância e desvalorização a mulher faz ciência, ela pesquisa, ela produz, e mesmo com tanta desigualdade e dificuldade que ainda encontram elas são maioria em muitos campos, nas ciências da saúde, na educação e na área de humanas. É neste contexto, que pensar gêneroassociado na carreira científica contribui para a importante discussão a respeito das disparidades. Nos ajuda a entender porque ainda hoje a mulher está em minoria nas áreas das exatas e continuam nas carreiras feminizadas. Permite compreender que conforme o grau de exigência de cada área, mais escassa é a presença da mulher, devido às relações sociais e às construções históricas baseadas nas relações de poder que construíram em torno do feminino,uma concepção distorcida de inaptidões naturais que levaram elas a invisibilidade nas carreiras.

\section{CONCLUSÃO}

Criar Educação, Criciúma, v. 7, no2, julho/novembro 2017.- PPGE - UNESC 
$O$ avanço da mulher na carreira científica é resultado de muito esforço e também de investimentos nestes campos. A abertura do ensino universitário para a mulher, contribuiu para mostrar a capacidade que elas têm de superar muitos obstáculos e enfrentar a discriminação existente. A rigorosidade e as exigências nas carreiras masculinizadas como no caso da carreira científica,tem criado dificuldades de acesso e participação feminina. $O$ fato é que a discriminação existente foi construída historicamente, mas hoje em pleno século XXI e com todos os avanços da mulher na carreira científica ainda há estudos que comprovam a dificuldade delas em alcançar as áreas mais duras da ciência e os cargos de maior prestígio. Sabemos que esta dificuldade não é devido a sua incapacidade intelectual, mas sim baseada na desigualdade de gênero, resultado de relações sociais e de poder que a sociedade construiu para determinar os espaços masculinos e femininos, como espaços limitados ao público e privado, respectivamente, além de determinar a existência de um ser dominante, o homem, capaz de ocupar os espaços públicos e afastar a mulher da sociedade a confinando na esfera doméstica.

Com a expansão da mulher no mercado de trabalho e seu acesso a educação muitas conquistas e portas foram se abrindo, muitas barreiras foram rompidas, embora a mulher ainda tenha pouca visibilidade para a ciência, elas estão em grande número e contribuem massivamente na produção de saberes. Ainda restam obviamente, muitos desafios a serem enfrentados e muito a se alcançar, mas é preciso eliminar as dificuldades e diminuira desigualdade entre homens e mulheres. É fundamental que a sociedade reconheça que a mulher é capaz de ocupar espaços que hoje os homens ocupam.

Para auxiliar nesta jornada discutir gênero é necessário e fundamental, visto que a discriminação contra a mulher é algo enraizado em nossa sociedade e impossibilita os avanços femininos nos campos científicos. Quebrando as barreiras existentes podemos alcançar, quem sabe um dia, a equidade de gênero e o reconhecimento do trabalho feminino. Por enquanto sabemos que há um grande percurso a ser feito para que diminuir ou até acabar com a sub-representação feminina na ciência. 


\section{REFERÊNCIAS}

ALMEIDA, Jane Soares de. Mulher e educação: a paixão pelo possível. São Paulo: Ed. UNESP, 1998. 225 p. (Coleção prismas )

BANDEIRA, Lourdes. A contribuição da crítica feminista à ciência. Estudos Feministas, v. 4, n. se, p. 0-0, 2008.

BARROSO, Carmen. Mulher, sociedade e estado no Brasil. Brasília: Ed. Brasiliense, 1982. $190 \mathrm{p}$.

CARVALHO, Marilia Gomes de;CASAGRANDE, Lindamir Salete. Mulheres e ciência: desafios e conquistas. Interthesis: Revista Internacional Interdisciplinar, v.8,n.2,p.20-35, 2011. Acesso em 20/01/17 Disponívelem: https://periodicos.ufsc.br/index.php/interthesis/article/view/1807$\underline{1384.2011 \mathrm{v} 8 \mathrm{n} 2 \mathrm{p} 20 / 0}>$

FERRAND, Michèle. A exclusão das mulheres da prática das ciências Uma manifestação sutil da dominação masculina. Estudos Feministas, p. 358-367, 1994. Acesso em: 20/11/16 Disponível em: https://periodicos.ufsc.br/index.php/ref/article/view/16169/0

GUEDES, Moema de Castro. Gênero e Ciência: uma análise das mulheres nas carreiras acadêmicas no Brasil. Acesso em 20/10/16

Disponível em: $<$ http://actacientifica.servicioit.cl/biblioteca/gt/GT11/GT11 deCastroGuedesM.pdf>

GOMES, Beatriz de Azevedo; SIQUEIRA, Vera Helena Ferraz de. Questões de gênero na carreira de professoras universitárias na área /das ciências biomédicas.Acessado em: 17/01/2017Disponível em: $<$ http://www.fazendogenero.ufsc.br/9/resources/anais/1278282211 ARQUIVO ARTI GOFAZENDOGENEROFINAL.pdf>

KOVALESKI, Nádia VeroniqueJourda; TORTATO, Cintia Souza Batista; Criar Educação, Criciúma, v. 7, no22, julho/novembro 2017.- PPGE - UNESC 
CARVALHO, Marilia Gomes de. As relações de gênero na história das ciências: Contra todas as probabilidades, as mulheres participaram do progresso científico e tecnológico. Emancipação, v. 13, n. 3, p. 9-26, 2013.

LAGRAVE, Rose -Marie. Uma emancipação sob tutela. Educação e trabalho das mulheres no século XX. In: DUBY, Georges (Ed.). História das mulheres no Ocidente. Porto: Afrontamento, 1990-1991. 5 v.

LOURO, Guacira Lopes. Gênero, sexualidade e educação: uma perspectiva pósestruturalista. 2. ed. Petrópolis: Ed. Vozes, 1998. 179 p

MARIA LÚCIA. Tecendo por trás dos panos: a mulher brasileira nas relações familiares. Rio de Janeiro: Rocco, 1994. 249 p.

MELO, Hildete Pereira de; RODRIGUES, Lígia Maria C. S. Pioneiras da ciência no Brasil. Acesso em: 22/11/16 Disponível em http://cnpq.br/pioneiras-da-cienciado-brasil

MARQUES, Fabrício. Poder Feminino.Recorde de laureadas mostra como cresce a presença das mulheres no topo da ciência. Política C\&T. Ed. 165. Fapesp. Acesso em: $20 / 01 / 17$

Disponíve em:<http://revistapesquisa.fapesp.br/2009/11/01/poder-feminino/>

PINSKY, Carla Bassanezi; PEDRO, Joana Maria. Mulheres: igualdade e especificidade. In: PINSKY, Jaime; PINSKY, Carla Bassanezi (orgs.). História da cidadania. São Paulo: Contexto, 2003. p.265-309.

COUTINHO, Maria Lúcia Rocha. Tecendo por trás dos panos: a mulher brasileira nas relações familiares. Rio de Janeiro: Rocco, 1994. 249 p.

SAFIOTTI, Heleieth. Conceituando Gênero. São Paulo; Secretaria Municipal de Educação. Coordenadoria Especial da Mulher; Jun.2003. 88 p. Gênero e Educação: caderno de apoio para a educadora e o educador / Genderandeducation: notebook ofsupport for educator.

SCOTT, Joan W. A mulher trabalhadora. In DUBY, Georges (Ed.). História das mulheres no Ocidente. Porto: Afrontamento, 1990-1991. 4 v.

THÉBAUD, Françoise. A grande Guerra. In: DUBY, Georges (Ed.). História das Criar Educação, Criciúma, v. 7, n², julho/novembro 2017.-PPGE - UNESC 
mulheres no Ocidente. Porto: Afrontamento, 1990-1991. 5 v.

YANNOULAS, Silvia Cristina. Feminização ou feminilização? Apontamentos em torno de uma categoria. Temporalis, Brasília (DF), ano 11, n.22, p.271-292, jul./dez. 2011. Acesso em: 25/11/16

Disponível em: http://periodicos.ufes.br/temporalis/article/view/1368/1583 